\title{
Borrowing Constraints and Technology Diffusion: Implications of Intra-Industry Trade (Job Market Paper)
}

\author{
Yong Kim* \\ London School of Economics
}

November 15, 2001

\begin{abstract}
This paper develops a theory of total factor productivity differences in a framework of technology diffusion. I show how in countries with tighter borrowing constraints, frontier technologies diffuse more slowly, and old outdated technologies continue to be used. I analyse how countries with different borrowing constraints specialise across new and old technologies through two forms of intra-industry trade. First, I consider international factor mobility which is interpreted as a form of (vertically differentiated) intermediate goods trade. Second, I consider trade in (vertically differentiated) final goods. Under both forms of trade, poor countries with tighter borrowing constraints exploit their comparative advantage through specialising in older technologies. However, under international factor mobility, poor countries can adopt new technologies faster by gaining access to inputs which complement the use of newer technologies. The patterns of specialisation across technologies are dramatically different under each form of trade. Despite this, both forms of trade are consistent with total factor productivity divergence between countries with different borrowing constraints.
\end{abstract}

Keywords Borrowing constraints; Technology diffusion; Total factor productivity; Intra-industry trade

JEL Classification J24; J31; O3; F1; F2

${ }^{*}$ Acknowledgements: I thank my advisor Nobu Kiyotaki for numerous discussions and his patience. Address: Department of Economics, London School of Economics, Houghton Street, London, WC2A 2AE, United Kingdom. Tel.: +44-20-7955 7487. Email: y.kim@lse.ac.uk 


\section{Introduction}

An emerging view attributes much of the differences in per capita income levels across countries, to differences in total factor productivity (TFP). ${ }^{1}$ This has motivated Prescott (1998) to call for a "theory of TFP differences". If technologies are in the international public domain, an explanation for these persistent TFP differences must be framed in terms of differences in barriers to the adoption of new, high TFP technologies [Parente and Prescott (1994)]. More specifically, a theory of TFP differences needs to address two observations: (i) why is the diffusion of frontier technologies slower in poor countries, and (ii) why do poor countries continue to use and invest in old technologies which have long been discarded from production in rich countries?

This paper develops a theory of TFP differences in a framework of technology diffusion. The source of my TFP differences are exogenous differences in borrowing possibilities, which result from differences in the quality of institutions which enforce external investor rights. When new technologies are associated with higher "investment" relative to old technologies, tighter borrowing constraints lower output by distorting the allocation of inputs away from high investment activities to low investment activities.

I go on to consider the impact of intra-industry trade on the magnitude of the TFP differences which arise. A running debate in the empirical literature on international technology diffusion is why increased trade and technology transfer between rich and poor countries leads to ambiguous effects on the TFP of poor countries, and ambiguous effects on convergence in TFPs between rich and poor countries [Coe and Helpman (1995), Keller (1998), Rodriguez and Rodrik (1999)]. Among different forms of trade, this literature finds stronger evidence of TFP growth in poor countries looking at intermediate goods trade alone [Coe, Helpman and Hoffmaister (1997), Meyer(2001)]. ${ }^{2}$ I set out to show how despite trade, the TFP differences which arise from differences in borrowing constraints do not subside. Indeed, under some forms of trade, TFP differences diverge.

\footnotetext{
${ }^{1}$ Klenow and Rodrigues-Clare (1997), and Hall and Jones (1999) conclude that about $50 \%$ of per capita income differences can be traced to TFP differences.

${ }^{2}$ Keller (2001) provides an up to date review of this literature.
} 
I address the heterogeneity of TFP outcomes under different forms of trade by considering two forms of intra-industry trade. First, I analyse international mobility of factor inputs and go on to interpret this as a form of (vertically differentiated) intermediate goods trade. Second, I analyse trade in (vertically differentiated) final goods. In this process, I clarify the interaction between two intuitive forces of intra-industry trade. First, trade leads poor countries to further specialisation in low income, old technologies for which they have a comparative advantage (a force for lower incomes). Second, trade leads poor countries to adopt new technologies faster (a force for higher incomes). In my framework, this occurs when international factor mobility gives poor countries access to stocks of "capital", which complement new investment into newer technologies . Under international factor mobility both forces of trade are present, under final goods trade only the first force is present.

Three results summarise my findings. The pattern of specialisation across technologies is dramatically different under each form of trade. International factor mobility is consistent with TFP convergence or divergence between countries with different borrowing constraints. Trade in final goods is inconsistent with TFP convergence between countries with different borrowing constraints.

Chari and Hopenhayn (1991) present a canonical analysis of technology diffusion in their "vintage human capital" model. The application of that framework to borrowing constraints and intra-industry trade constitutes the core of my paper. Among models of technology diffusion the vintage human capital model is unique in predicting continued entry and investment in old technologies. Other models of diffusion which rely on uncertainty of new technologies, strategic issues, or spillover effects seem inappropriate to the question at hand.

The exogenous role of enforcement institutions on economic performance is motivated by the literature on financial development (or deepening) and growth. The quality of enforcement institutions are directly linked to the volume of financial trade in an economy. In early seminal work, Goldsmith (1969) established a correlation between economic and financial development by measuring the value of financial intermediary assets to GNP, while country case studies by Cameron (1967) dissected historical relationships between 
banking development and early industrialisation to suggest that the former had an independent and positive growth-inducing role. The modern revival of empirical studies begins with King and Levine (1993) and is reviewed in Levine (1997).

These studies do not unambiguously resolve the issue of causality between enforcement institutions and growth, but recent progress has been made on this front. La Porta, Lopez-de-Silanes, Shleifer and Vishny $(1997,1998)$ show how various measures of investor rights are systematically linked to the legal origin of enforcement institutions. Since countries typically adopted one of four legal systems (English, French, German, Scandinavian) through occupation or colonisation, the implied differences in investor rights are seen as exogenous. In the literature on finance and growth, the La Porta, Lopez-de-Silanes, Shleifer and Vishny indices of investor rights and legal origin are used as instruments to extract the exogenous component of financial development and control for simultaneity bias. In particular, studies find that the main channel through which financial development and investor rights affect growth is through TFP rather than through savings or capital accumulation levels [Beck, Levine and Loayza (2000), Wurgler (2000)]. Instead of highlighting the identity of colonisers, Acemoglu, Johnson and Robinson (2001) argue that the conditions for settlement by colonisers came to determine institutional quality. Using colonialist mortality rates as instruments for institutional quality, they find large effects of this variable on current per capita income levels. $^{3}$

Although the environment studied is inherently dynamic, it is possible to introduce many of the main mechanisms of the theory in terms of a simple static economy (readers may skip this by going to the penultimate paragraph of the introduction). Consider a stationary two period overlapping generations economy, where ex ante identical agents can become entrepreneurs or workers. Workers earn a constant wage in both periods of their lives. Entrepreneurs hire workers from competitive labour markets and maximise profits subject to a production function which is concave in worker inputs. To become

\footnotetext{
3 On the other hand, Rajan and Zingales (2001) show that financial development may not be monotonic over time, and propose an interest group theory of financial development. My argument only relies on stable differences in enforcement institutions, and remains valid as long as institutions are not endogenous to the other variables under analysis.
} 
an entrepreneur, every agent must acquire skills through learning-by-doing in youth, and in youth such agents receive a fixed income. Equilibrium wages equalise the utility of ex ante identical agents across occupations. Since entrepreneurs earn more than workers, lifetime earnings profiles are steeper for agents planning to become entrepreneurs, and such agents are "investing" in youth in terms of foregone earnings.

Suppose agents have concave utility functions over consumption in each period of their lives. Compare outcomes when subject to budget constraints $(i)$ young agents can borrow as much as they like, and (ii) they can only commit a fixed share of their old period incomes as collateral for loans: borrowing constraints. In the first case, equilibrium wages equalise discounted lifetime earnings across occupations. In the second case, the equilibrium wage is lower, because borrowing constraints have a greater disutility effect on young agents with steeper earnings profiles, who plan to become entrepreneurs. In this second case, although lifetime utilities are lower, discounted lifetime earnings are higher for entrepreneurs. Meanwhile, for workers, discounted lifetime earnings are lower. Since entrepreneurs' input demands are higher, the share of entrepreneurs in the economy must fall. Borrowing constraints lower aggregate output by distorting the allocation of workers across the two occupations.

Next, suppose that the two cases describe two coexisting economies in the world, and consider outcomes under free international mobility of agents (i.e. factor price equalisation). Let every young agent be subject to the borrowing constraints prevailing in her country of origin. Agents who do not face borrowing constraints are sorted into steep earnings profile occupations (entrepreneurs), while agents who face borrowing constraints are sorted into shallow earnings profile occupations (workers). Consider two possible outcomes. If all agents from the borrowing constrained economy become workers, the discounted value of lifetime earnings are equalised across the world. If all agents from the borrowing unconstrained economy become entrepreneurs, agents from this economy have higher discounted lifetime earnings, while average discounted lifetime earnings for the economy with borrowing constraints falls. International mobility of agents does not necessarily imply that lifetime earnings converge across economies.

Earnings outcomes under international mobility of agents are identical to outcomes 
where only entrepreneurs are internationally mobile. Suppose one reinterprets the mobility of entrepreneurs as the mobility of intermediate goods that they produce: i.e. workers are indifferent between working with entrepreneurs or working with intermediate goods that entrepreneurs produce. Then, outcomes under international mobility are interpreted as those under trade in intermediate goods. This analysis already captures two different forces associated with intermediate goods trade. First, agents from economies differentiated by borrowing constraints exploit their comparative advantage by increased specialisation across occupations. Second, intermediate goods trade allows agents in the poorer, borrowing constrained economy to participate in a more efficient use of the given technologies.

Now consider final goods trade. Suppose there is no mobility of agents or intermediate goods trade. In each period, a new "fashion" introduces a differentiated good and agents can become fashion specific entrepreneurs through learning-by-doing in youth. It takes one period for a new good to become unfashionable, and all unfashionable goods are perfect substitutes. Although all entrepreneurs and workers produce one period old unfashionable goods, next period's entrepreneurs produce a fixed amount of fashionable goods in the current period. The relative price of fashionable goods is increasing in the scarcity of fashionable goods relative to unfashionable goods. Suppose our two coexisting economies do not engage in any final goods trade. Since there are fewer entrepreneurs in the borrowing constrained economy, in every period the fashionable good is relatively scarce, and the relative price of fashionable goods is higher.

Next, suppose there is trade in fashionable and unfashionable goods. In the borrowing constrained economy, the relative price of fashionable goods will fall. Just like the effect of tighter borrowing constraints, this has a greater disutility effect on young agents who plan to become entrepreneurs, so equilibrium worker wages will fall. In the economy without borrowing constraints the relative price of fashionable goods will rise. This has a greater utility effect on young agents who plan to become entrepreneurs, so equilibrium worker wages will rise. As in the case of intermediate goods trade, the allocation of labour across occupations diverges as a result of trade. This captures the fact that economies exploit their comparative advantage across occupations. However, unlike the case with 
intermediate goods trade, this is the result of diverging factor prices (worker wages). Final goods trade is not associated with agents in the borrowing constrained economy participating in a more efficient use of the given technologies. Overall, the TFPs of the two economies must diverge.

In the general framework considered, there is an (exogenously) ever-growing set of technologies which can be ranked according to their TFP. Within each technology, entrepreneurs hire workers to maximise profits. Young agents can become technology specific entrepreneurs through acquiring skills as technology specific workers in youth. Since entrepreneurs in new technologies are more productive, young workers entering relatively older technologies are compensated with higher wages in youth, and this ensures that entrepreneurs in newer technologies earn more than entrepreneurs in older technologies. Earnings profiles are steeper, the newer the technologies that young workers enter into. The number of coexisting technologies (and occupations) is endogenous and is determined by the youngest technology such that old, skilled agents in that technology prefer to be workers in another technology rather than utilising their skills as entrepreneurs. The mechanisms introduced above are considerably strengthened and clarified by endogenising the number of coexisting occupations which agents choose to participate in. In particular, I show how tighter borrowing constraints cause frontier technologies to diffuse more slowly, and prolong the use of old technologies.

My theory of TFP differences complements existing work which has considered monopoly rights [Parente and Prescott(1999)], vested interests [Krusell and Rios-Rull (1996)], capital labour ratios [Basu and Weil (1998)] and ratios of skilled to unskilled labour [Acemoglu and Zilibotti (2000)]. Section 1 presents the basic model and conducts comparative statics with borrowing constraints. Section 2 applies the model to trade in international factor mobility and trade in final goods. The last section concludes with suggestions for future research. 


\section{Model}

\subsection{Preferences}

Consider a two period overlapping generations economy, populated exclusively by ex ante identical agents who have preferences of the Cobb-Douglas form,

$$
u=\sqrt{c_{1} c_{2}}
$$

$c_{1}$ denotes consumption in youth, and $c_{2}$ denotes consumption in old age. A constant population of agents is born every period. Agents can borrow from international capital markets, and face an exogenous world interest factor $R>1$. Let $y_{1}$ and $y_{2}$ denote young and old period earnings respectively. The lifetime budget constraint of a worker is,

$$
c_{1}+\frac{1}{R} c_{2}=y_{1}+\frac{1}{R} y_{2}
$$

In credit markets, the imperfect enforcement of investor rights means that young agents can only borrow up to a fraction $\theta$, of their discounted old period earnings for young period consumption,

$$
c_{1}-y_{1} \leq \theta \frac{1}{R} y_{2}
$$

Borrowing constraints arise because borrowers cannot credibly commit to use more than a fraction $\theta$ of their old period earnings as collateral. ${ }^{4}$

\subsection{Technology}

Agents inhabit a "vintage human capital" economy. In every period, a frontier technology is exogenously introduced whose TFP is $\gamma>1$ times greater than the TFP of last period's frontier technology. Let $\tau \in\{0,1,2, \ldots\}$ index the vintage or age of a technology in period $t$, relative to the newest technology in that period (this implies that the identity of technology $\tau$ changes every period). Date $t$ output in technology $\tau$, is a constant returns to scale function of skilled labour $Z_{\tau, t}$, and unskilled labour $N_{\tau, t}$ inputs,

$$
F_{\tau, t}\left(Z_{\tau, t}, N_{\tau, t}\right)=\gamma^{t-\tau} F\left(Z_{\tau, t}, N_{\tau, t}\right) \equiv \gamma^{t-\tau} Z_{\tau, t} f\left(n_{\tau, t}\right)
$$

\footnotetext{
${ }^{4}$ The inalienability of future earnings from agents means that the ex post expropriation problem is particularly severe in this situation (compared to borrowing against physical capital) and the role of third party enforcement of investor rights is important.
} 
$n_{\tau, t}$ denotes the number of unskilled agents per skilled agent in vintage $\tau$. The assumption of constant returns implies that $F(0, N)$ is linear in $N$ : define $F(0,1) \equiv \omega_{0} \geq 0$.

Although newer technologies have higher TFP, older technologies will continue to be used in the economy if skilled and unskilled labour are complements in production, $F_{Z N}>0$. This crucial assumption introduces a trade-off between adopting new technologies with higher TFP, but where skilled labour is scarce, versus the continued use of old technologies where skilled labour is abundant but TFP is low.

Every agent acquires technology specific skills through learning-by-doing in youth. All young agents are unskilled. I refer to all unskilled labour as "workers". All old agents are skilled, and may utilise their skills as technology specific "entrepreneurs" who hire workers from competitive labour markets to maximise their earnings. Let $w_{\tau, t}$ denote the period $t$ earnings of a worker in technology $\tau$. The optimal earnings of an entrepreneur in the corresponding technology is, ${ }^{5}$

$$
\pi_{\tau, t}\left(w_{\tau, t}\right)=\max _{n} \gamma^{t-\tau} f\left(n_{\tau, t}\right)-n_{\tau, t} w_{\tau, t}
$$

A young worker who enters technology $\tau-1$ in period $t-1$, earns $w_{\tau-1, t-1}$ in youth and becomes skilled in technology $\tau$ in period $t$. When old this agent is free be an entrepreneur to earn $\pi_{\tau, t}\left(w_{\tau, t}\right)$ or exercise the option of being an old worker in any other technology. Assume that skilled agents choose to be entrepreneurs only if they are strictly better off doing so: $\pi_{\tau, t}\left(w_{\tau, t}\right)>\max _{s} w_{s, t}$. Note that young workers in the frontier technology necessarily produce by themselves to earn $w_{0, t}=\gamma^{t} F(0,1) \equiv \gamma^{t} \omega_{0}$. To summarise, the combination of young and old period earnings for this generic agent who is young in period $t-1$ is given by,

$$
\left(y_{1, t-1}, y_{2, t}\right)=\left(w_{\tau-1, t-1}, \max \left\{\pi_{\tau, t}\left(w_{\tau, t}\right), \max _{s} w_{s, t}\right\}\right)
$$

At each moment of time, agents are distributed across technologies of different ages relative to the frontier technology. Let $\mu_{\tau, t}$ denote the share of old agents in the population who are skilled in technology $\tau$, and $\mu_{t}$ the entire distribution. Since period $t$ skilled agents in technology $\tau$, were period $t-1$ workers in technology $\tau-1$, we know that $\mu_{\tau-1, t-1} n_{\tau-1, t-1} \geq \mu_{\tau, t}$ for $\forall \tau \geq 1$.

\footnotetext{
${ }^{5}$ Since $F_{Z N}>0 \Leftrightarrow f^{\prime \prime}(n)<0$, the solution to the entrepreneur's maximisation problem is unique.
} 


\subsection{Equilibrium}

In a competitive equilibrium: in every period (i) each young worker chooses which technology specific skill to acquire, how much to earn and consume across periods in order to maximise lifetime utility (1) subject to the interest factor $R$, and the constraints (2), (3) and (6); (ii) old agents maximise their earnings and (iii) the labour markets for technology specific workers clear.

The indirect utility of young workers, $v\left(y_{1}, y_{2} ; \theta, R\right)$ can be rearranged to express utility as the product of the present discounted value of earnings, a constant $\frac{\sqrt{R}}{2}$, and a fraction,

$$
\begin{aligned}
v\left(y_{1}, y_{2} ; \theta, R\right)= & \left(y_{1}+\frac{1}{R} y_{2}\right) \frac{\sqrt{R}}{2} \text { if borrowing constraints do not bind } \\
& \sqrt{\left(y_{1}+\frac{\theta}{R} y_{2}\right)(1-\theta) y_{2}} \text { if borrowing constraints bind } \\
& \left(y_{1}+\frac{1}{R} y_{2}\right) \frac{\sqrt{R}}{2} \min \left\{1,2\left(\frac{\sqrt{(1-\theta)\left(R \frac{y_{1}}{y_{2}}+\theta\right)}}{R \frac{y_{1}}{y_{2}}+1}\right)\right\} \\
& \equiv\left(y_{1}+\frac{1}{R} y_{2}\right) \frac{\sqrt{R}}{2} \delta\left(R \frac{y_{1}}{y_{2}} ; \theta\right)
\end{aligned}
$$

This separates out the effects on utility of (i) the level of present discounted earnings and

(ii) borrowing constraints and the steepness of the earnings profile. Let $\delta\left(R \frac{y_{1}}{y_{2}} ; \theta\right) \in$ $(0,1]$ denote the "lifetime earnings discount factor". $\delta\left(R \frac{y_{1}}{y_{2}} ; \theta\right)$ is equal to 1 only if borrowing constraints do not bind, is increasing in the level of borrowing constraint $\theta$, $\frac{\partial \delta}{\partial \theta} \geq 0$, and is increasing in the ratio of earnings $\frac{y_{1}}{y_{2}}, \frac{\partial \delta}{\partial \frac{y_{1}}{y_{2}}} \geq 0$. The cross partial, $\frac{\partial^{2} \delta}{\partial \frac{y_{1}}{y_{2}} \partial \theta} \leq 0$ captures the fact that the indifference curves of agents who face different $\theta$ will be single crossing in the space of young and old period earnings.

This characterisation of indirect utility will assist the analysis of equilibrium outcomes throughout the paper. Using (6), denote the "lifetime earnings discount factor" for the generic agent who is young in period $t-1$ as,

$$
\delta_{\tau, t}=\delta_{\tau, t}\left(R \frac{w_{\tau-1, t-1}}{\max \left\{\pi_{\tau, t}\left(w_{\tau, t}\right), \max _{s} w_{s, t}\right\}} ; \theta\right)
$$

Since ex ante identical young workers are utility maximisers, the earnings path for each technology with positive entry by young agents must yield an indirect utility at 
least as high as any other technology,

$$
\begin{aligned}
& \left(w_{\tau-1, t-1}+\frac{1}{R} \max \left\{\pi_{\tau, t}\left(w_{\tau, t}\right), \max _{s} w_{s, t}\right\}\right) \delta_{\tau, t} \\
\geq & \left(w_{\nu-1, t-1}+\frac{1}{R} \max \left\{\pi_{\nu, t}\left(w_{\nu, t}\right), \max _{s} w_{s, t}\right\}\right) \delta_{\nu, t}
\end{aligned}
$$

for all $\tau, \nu$ such that $n_{\tau-1}>0$.

I restrict analysis to that of stationary competitive equilibrium. Such an equilibrium is a collection of earnings profiles $w_{\tau, t}, \pi_{\tau, t}\left(w_{\tau, t}\right)$; input demands $n_{\tau, t}$; distribution functions $\mu_{t}$ such that,

(i) The distribution of agents across technologies is stationary $\mu_{\tau, t}=\mu_{\tau}$, input demands are stationary $n_{\tau, t}=n_{\tau}$, and earnings profiles grow at a constant rate $w_{\tau, t}=\gamma^{t} w_{\tau}, \pi_{\tau, t}\left(w_{\tau, t}\right)=\gamma^{t} \pi_{\tau}\left(w_{\tau}\right)$.

(ii) Young workers are indifferent among technologies they enter into (9), and old agents maximise their earnings.

(iii) The full employment condition is satisfied: $\sum_{\tau=1}^{\infty} \mu_{\tau}=1 .^{6}$

A stationary equilibrium is characterised by an invariant distribution of agents relative to a constantly changing frontier technology. Although earnings levels are steadily increasing, the "lifetime earnings discount factors" across vintages are stationary since they are functions of the ratio of young and old period earnings. The restriction to stationary outcomes means that time indices will be dropped throughout the rest of the paper.

Proposition 1 A unique stationary competitive equilibrium exists where,

(i) the terminal vintage is finite $T<\infty$

(ii) skilled agents in vintages 1 to $T-1$ are entrepreneurs, so $\mu_{\tau}=n_{\tau-1} \mu_{\tau-1}$; young workers who enter vintage $T-1$ remain workers in vintage $T-1$ when old, so $\mu_{T}=\frac{n_{T-1}}{2} \mu_{T-1}$ (iii) worker wages are increasing in vintage $w_{\tau+1}>w_{\tau}$, so $n_{\tau+1}<n_{\tau}$

(iv) the lifetime earnings discount factor is increasing in vintage $\delta_{\tau+1} \geq \delta_{\tau}$ Proof in Appendix.

\footnotetext{
${ }^{6}$ In stationary states, this ensures that the full employment constraint of young workers is automatically satisfied.
} 
When faced with a given worker wage, entrepreneurs in older vintages are less productive. Young workers are compensated to enter older vintages through higher worker wages. This in turn ensures that entrepreneur earnings are falling in vintage. Eventually, the worker wage which would warrant entry into a very old vintage (vintage $T$ ) exceeds the optimised entrepreneur earnings of that vintage such that that vintage and older vintages are not used in production. The slope of the lifetime earnings profile is steeper for those who enter younger vintages. Since $\delta_{\tau}$ is falling in the steepness of the lifetime earnings profile, the present discounted value of lifetime earnings is falling in vintage. ${ }^{7}$

In equilibrium, the indifference condition across coexisting vintages is given by,

$$
\begin{aligned}
\left(\omega_{0}+\frac{\gamma}{R} \pi_{1}\left(w_{1}\right)\right) \delta_{1} & =\left(w_{1}+\frac{\gamma}{R} \pi_{2}\left(w_{2}\right)\right) \delta_{2}=\ldots \\
& =\left(w_{T-2}+\frac{\gamma}{R} \pi_{T-1}\left(w_{T-1}\right)\right) \delta_{T-1} \\
& =\left(w_{T-1}+\frac{\gamma}{R} w_{T-1}\right) \delta_{T}
\end{aligned}
$$

Young workers who enter the frontier technology necessarily produce by themselves so earn $w_{0}=\omega_{0}$.

The highest worker wage in the economy is weakly lower than the entrepreneur earnings of the penultimate technology, and strictly higher than the entrepreneur earnings of the terminal technology. Thus, $w_{T-1}$ serves as an index of the number of vintages in use in the economy,

$$
\pi_{T-1}\left(w_{T-1}\right)>w_{T-1} \geq \pi_{T}\left(w_{T-1}\right)
$$

Inequalities (10) and (11) are used to iteratively solve for $T$ and the $T-1$ worker wages. The implied input demands across vintages, (ii) from Proposition 1 and the full employment constraint are combined to solve for $\mu_{1}$ first, and then the density of old agents across older vintages.

For vintages 1 to $T-2$, Proposition 1 ( $i i$ ) says that the growth factor of skilled agent density is exactly given by the input demands $n_{\tau}$, while for vintage $T-1$, this growth factor is given by half the input demand. Since input demands are falling in vintage,

\footnotetext{
${ }^{7}$ Thompson (1999) tests whether earnings profiles are steeper in newer technologies using historical data from the Canadian Maritime History Archive. He investigates the variation in wages across three vessel technologies (steam, barques and riggers) and finds strong support for this prediction.
} 
there exists a vintage $S$, such that $n_{\tau}<1$ for all $\forall \tau \geq S$. Combining this with (ii) from Proposition 1 implies that the density function of skilled agents across vintages is single peaked at technology $S$. The vintage with peak density is one way to think about the rate of technology diffusion: the time elapsed between the introduction and peak usage of a technology. I adopt this definition of diffusion throughout.

When a technology is introduced, it is first learned by young workers producing alone.

As the technology ages, the supply of entrepreneurs per worker increases $\frac{1}{n_{\tau}}>\frac{1}{n_{\tau-1}}$, such that workers can exploit the complementarities in skilled and unskilled labour to a greater extent. The process through which as a technology ages, workers can earn progressively higher wages while learning a given set of skills, is how I will define the process of technology "standardisation" in this paper.

\subsection{Differences in borrowing constraints}

In this section, I perform comparative statics on the economy by varying the degree of borrowing constraint $\theta$. Note that since labour endowments and the level of skills acquired by workers are held constant, any aggregate output differences resulting from varying the borrowing constraint $\theta$, are TFP differences. A simple example is used to flesh out the main results, then the general result is presented and a discussion of implications follows. Consider an equilibrium economy where $T=2$, and borrowing constraints are binding for young workers who enter the frontier technology (i.e. $\delta_{1}<1$ ). Participation constraints determine the vintage 1 worker wage, given $\theta$ and $R$,

$$
\left(\omega_{0}+\frac{\gamma}{R} \pi_{1}\left(w_{1}\right)\right) \delta_{1}\left(R \frac{\omega_{0}}{\gamma \pi_{1}\left(w_{1}\right)} ; \theta\right)=\left(w_{1}+\frac{\gamma}{R} w_{1}\right) \delta_{2}\left(R \frac{1}{\gamma} ; \theta\right)
$$

These two earnings paths can simply be referred to as new technology and old technology occupations. Using the results of Proposition 1 and the full employment constraint, the share of skilled agents in technology 2 is equal to half the input demand of skilled agents in technology 1 ,

$$
\mu_{2}=1-\mu_{1}=\mu_{1} \frac{n_{1}\left(w_{1}\right)}{2}
$$

This solves for the density of skilled agents across the two vintages. 
Now suppose that relative to this benchmark economy, young workers in another economy face lower borrowing constraints as a share of their future income, $\theta>\hat{\theta}$. All variables relating to this second economy are denoted with hats. Since the new technology occupation has a steeper earnings profile, the marginal disutility of lower $\theta$ is greater for this earnings path and $\left|\triangle \delta_{1}\right|>\left|\triangle \delta_{2}\right|$. Intuitively, new technologies require more "investment" in terms of forgone earnings and lower borrowing constraints raise the "costs" of such investments. Indirect utility across occupations can only be equalised again if the relative present discounted value of earnings for the new technology occupation increases. The latter can only be achieved through a lower $\hat{w}_{1}<w_{1}$. Ironically, this implies that the earnings profile for the new technology occupation becomes steeper, and leads to a second round of reductions in $\delta_{1}$, and $w_{1}$ and so on. The second and further rounds of effects are made necessary by the fact that the worker wage for the newest technology is anchored at a technologically determined $\omega_{0}$.

From (13), multiplied reductions in $w_{1}$, and the implied increase in input demand $n_{1}\left(w_{1}\right)$, translate into a shift in the distribution of skilled agents away from the new technology occupation, $\hat{\mu}_{1}<\mu_{1}$. Since vintage 1 worker wages are lower, the terminal vintage conditions for $T=2$ in (11) may no longer be satisfied (i.e. $\left.\pi_{2}\left(\hat{w}_{1}\right)>\hat{w}_{1}\right)$ since it is now worthwhile for technology 2 skilled agents to be entrepreneurs. In this case, the number of coexisting vintages in the economy will expand, $\hat{T}>T$. These insights are generalised in the following Proposition:

\section{Proposition 2 Compare two economies with different borrowing} constraints $\hat{\theta}<\theta$, where $\delta_{1}<1$, then,

(i) $\hat{w}_{\tau}<w_{\tau}, n_{\tau}\left(\hat{w}_{\tau}\right)>n_{\tau}\left(w_{\tau}\right)$ for all $1 \leq \tau \leq T-1$, and $\hat{\delta}_{\tau} \leq \delta_{\tau}$ for all $\tau$ where $\mu_{\tau}>0$

(ii) the terminal vintage is older in the $\hat{\theta}$ economy $\hat{T} \geq T$

(iii) $\hat{\mu}$ stochastically dominates $\mu$,

$$
\sum_{\tau=1}^{S} \hat{\mu}_{\tau}<\sum_{\tau=1}^{S} \mu_{\tau} \text { for } \forall S<\hat{T}
$$

Proof in Appendix.

Recall that the density function for skilled agents across vintages peaks at the 


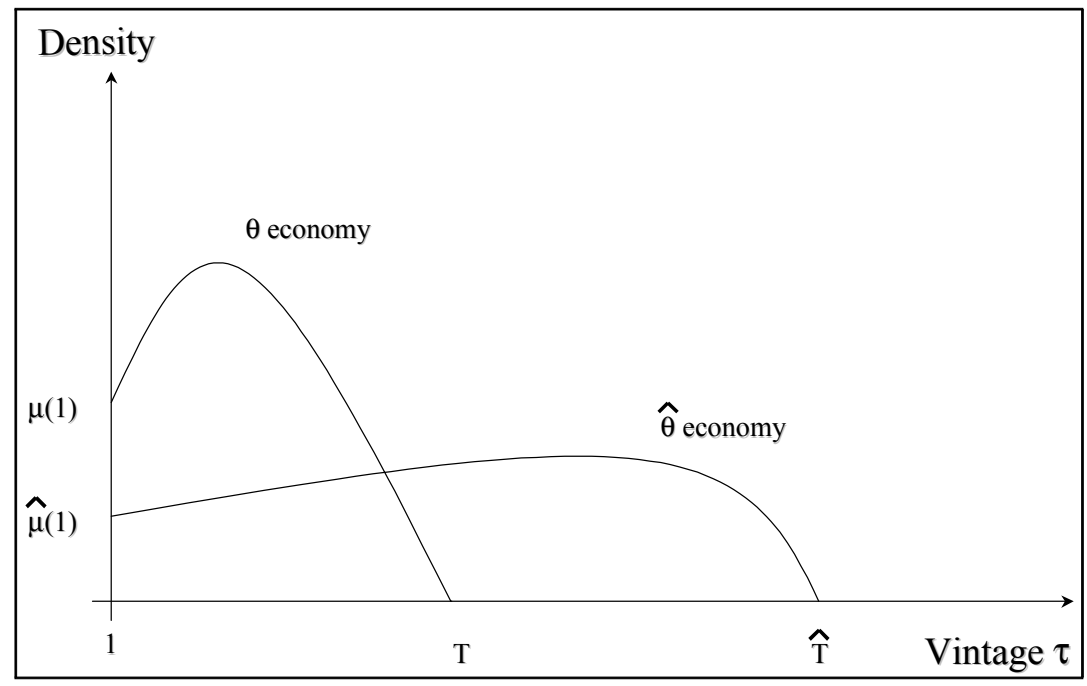

Figure 1: Density of agents across technologies

youngest vintage such that $n_{\tau}<1$. Higher input demand within a particular vintage, implies that the density function peaks at an older technology in the $\hat{\theta}$ economy. Thus, (i) technology diffusion is slower and (ii) a larger range of vintages coexist in the economy with lower borrowing constraints.

Consider the youngest vintage $Q \leq \hat{T}$, such that $\hat{\mu}_{Q}>\mu_{Q}$. The stochastic dominance result in Proposition 2 (iii) means that such a vintage exists. The higher input demand within vintages and the higher terminal vintage implies that $\hat{\mu}_{\tau}>\mu_{\tau}$ for $\forall Q \leq \tau \leq \hat{T}$, and $\hat{\mu}_{\tau}<\mu_{\tau}$ for $\forall 1 \leq \tau<Q$. [Figure 1] compares the density functions of skilled agents across vintages in the $\theta$ economy and $\hat{\theta}$ economy. Comparing stationary outcomes in these economies, young workers in the $\hat{\theta}$ economy are born into a higher absolute stock of skills in older vintages and a lower absolute stock of skills in new vintages. In this sense, it is more "appropriate" for young workers in poorer countries to work in older vintages. $^{8}$

\footnotetext{
${ }^{8}$ This interpretation has implications for the debate between two alternative approaches in analysing levels differences in per capita income. The factor neutral characteristic of TFP means that technologies are ranked along a single dimension, and there is a unique frontier technology in the world. An alternative approach first formulised by Atkinson and Stiglitz (1969), argues that the menu of technologies exhibits different degrees of efficiency bias toward specific factors of production, so countries with different factor endowments will choose different sets of "appropriate technologies". Caselli and Coleman (2000) find a negative cross country correlation between the efficiency of uneducated labour and educated labour, and present this as evidence in favour of the appropriate technology approach.
} 
A number of further differences in steady state outcomes arise. Lower worker wages within vintages and an older terminal vintage means that the lowest present discounted value of lifetime earnings is lower in the $\hat{\theta}$ economy: $\hat{w}_{\hat{T}-1}+\frac{\gamma}{R} \hat{w}_{\hat{T}-1}<w_{T-1}+\frac{\gamma}{R} w_{T-1}$. The highest discounted value of lifetime earnings in the $\hat{\theta}$ economy is higher: $\omega_{0}+\frac{\gamma}{R} \pi_{1}\left(\hat{w}_{1}\right)>$ $\omega_{0}+\frac{\gamma}{R} \pi_{1}\left(w_{1}\right)$. So more binding borrowing constraints increase the range of discounted lifetime earnings in the economy. Within a particular vintage, the steepness of the earnings profile is higher in the $\hat{\theta}$ economy: $\frac{\gamma \pi_{\tau}\left(\hat{w}_{\tau}\right)}{\hat{w}_{\tau-1}}>\frac{\gamma \pi_{\tau}\left(w_{\tau}\right)}{w_{\tau-1}}$. Given $\hat{\theta}<\theta$, the implied fall in the lifetime earnings discount factor, $\hat{\delta}_{\tau} \leq \delta_{\tau}$, means that within vintages, the efficiency with which earnings are converted into utility is lower in the $\hat{\theta}$ economy.

Since all entrepreneur earnings are higher and the highest worker wage is lower, the skill premium within vintages is higher in the $\hat{\theta}$ economy, $\pi_{\tau}\left(\hat{w}_{\tau}\right)-\hat{w}_{\hat{T}-1}>\pi_{\tau}\left(w_{\tau}\right)-w_{T-1}$ for $\forall \tau \leq \hat{T}$. For technologies where young workers face borrowing constraints, it is intuitive to expect the "reward" (skill premium) of "investment" (in terms of foregone earnings) to be higher if the "cost" of investment rises (lower borrowing constraints). However, the equilibrium effects also lead to higher skill premiums in older vintages which may not be subject to borrowing constraints.

Since input demands are lower within each vintage, $n_{\tau}\left(\hat{w}_{\tau}\right)<n_{\tau}\left(w_{\tau}\right)$, it takes longer for a particular ratio of entrepreneur per worker to be realised. This implies that workers in the $\hat{\theta}$ economy have to wait longer to command a given level of wages while learning a set of skills associated with a particular technology. Thus, tighter borrowing constraints slow the rate of technology standardisation.

[Figure 2] shows the equilibrium combinations of young and old period earnings of the two economies along their respective indifference curves. Since $\frac{\partial^{2} \delta}{\partial \frac{y_{1}}{y_{2}} \partial \theta} \leq 0$, differences in borrowing constraints imply that these indifference curves are single crossing. Suppose these two economies coexisted but there is no international worker mobility. Even if the

My analysis suggests a way to reconcile these two approaches. Differences in the stock of skills across technologies imply that econometric studies will detect higher per worker productivity (for a given measure of workers) in old technologies in poor countries, and higher per worker productivity in new technologies in rich countries. This is the case assuming econometric studies cannot differentiate between skilled and unskilled labour when skills are acquired through learning-by-doing (this is the case in Caselli and Coleman). Suppose educated agents are more likely to work in new technologies than uneducated agents. Then cross country results such as those of Caselli and Coleman would be consistent with the underlying TFP approach of my framework. 


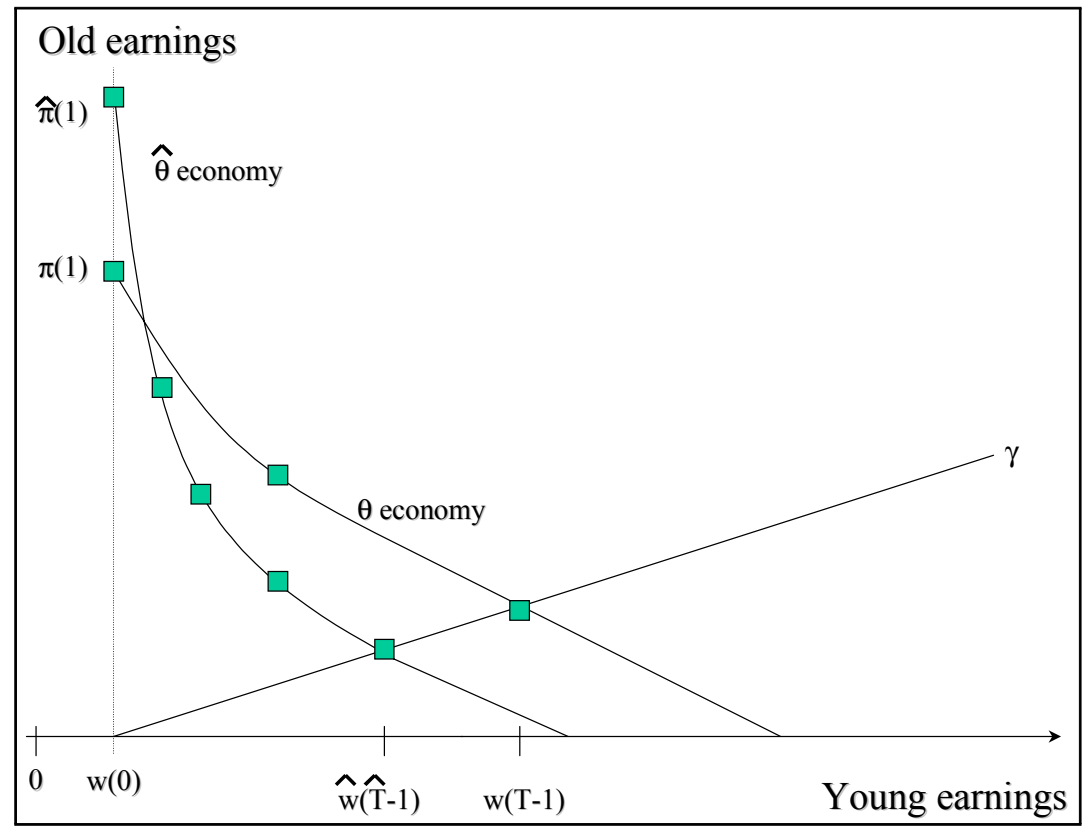

Figure 2: Earnings combinations with across technologies

degree of borrowing constraints that agents face are dependent on the economy of origin, young workers from the $\hat{\theta}$ economy, would prefer to migrate to the $\theta$ economy, and work in older technologies. Meanwhile, young workers from the $\theta$ economy, would prefer to migrate to the $\hat{\theta}$ economy, and work in newer vintages. Note that, workers in the $\hat{\theta}$ economy working in a relatively old vintage may observe in the $\theta$ economy shallower lifetime earnings profiles, in newer vintages with higher present discounted earnings.

\section{Intra-industry trade}

\subsection{International labour mobility as intermediate goods trade}

This section applies the basic model, with differences in borrowing constraints, to investigate patterns of specialisation across technologies which result from international labour mobility. Of course, the mobility of all factors of production must imply there is complete factor price equalisation. Note that since within vintages, workers produce with one other factor of production (entrepreneurs), it is sufficient for factor price equal- 
isation that only entrepreneurs are internationally mobile. ${ }^{9}$

It is possible to interpret outcomes under labour mobility as resulting from trade in vintage specific intermediate goods in the following way. Consider the earnings of entrepreneurs for each vintage as the price of vintage specific intermediate goods that they respectively produce. Each type of entrepreneur produces one unit of their vintage specific intermediate good. Within each vintage, the entrepreneur intermediate goods are combined with unskilled labour to yield output according to (4). Thus, workers are indifferent between producing with entrepreneurs and producing with intermediate goods produced by entrepreneurs. I return to this interpretation at the end of this section.

Consider two coexisting economies of equal size, economy $\theta$ and economy $\hat{\theta}$, where $\theta>\hat{\theta} .{ }^{10}$ The interest rate $R$ is constant. All agents are subject to the borrowing constraints prevailing in their country of origin. Under international mobility of labour, there is a "single economy" populated by two types of workers who face different borrowing constraints in youth. Denote by dashes all variables relating to outcomes for each economy in this single economy. Let $\mu^{W}$ denote the distribution of skilled agents across vintages in the world population. The density of skilled agents from the world population in vintage $\tau$ is given by $\mu_{\tau}^{W}=\frac{\mu_{\tau}^{\prime}+\hat{\mu}_{\tau}^{\prime}}{2}$. A stationary competitive equilibrium with labour mobility is defined as previously, subject to the following modifications. First, young workers in each economy are indifferent among only those vintages that their compatriots enter into; i.e. for the $\theta$ economy,

$$
\begin{aligned}
& \left(w_{\tau-1, t-1}^{\prime}+\frac{1}{R} \max \left\{\pi_{\tau, t}\left(w_{\tau, t}^{\prime}\right), \max _{s} w_{s, t}^{\prime}\right\}\right) \delta_{\tau, t}(\theta) \\
\geq & \left(w_{\nu-1, t-1}^{\prime}+\frac{1}{R} \max \left\{\pi_{\nu, t}\left(w_{\nu, t}^{\prime}\right), \max _{s} w_{s, t}^{\prime}\right\}\right) \delta_{\nu, t}(\theta)
\end{aligned}
$$

for all $\tau, \nu$ such that $n_{\tau-1}^{\prime}>0$, and similarly for the $\hat{\theta}$ economy. Second, the full employment constraint is now given by: $\sum_{\tau=1}^{\infty}\left[\mu_{\tau}^{\prime}+\hat{\mu}_{\tau}^{\prime}\right]=2$. Lemma 1 summarises the pattern of specialisation across vintages resulting from labour mobility.

\footnotetext{
${ }^{9}$ Or vice versa, only workers are internationally mobile.

10 There is another interesting dimension arising from the relative size of the two economies which is not explored here.
} 
Lemma 1 Let $F, \hat{F}$ denote the youngest vintage used by entrepreneurs in economy $\theta$ and economy $\hat{\theta}$. With international labour mobility, $1=F^{\prime} \leq \hat{F}^{\prime}$, and $T^{\prime} \leq \hat{T}^{\prime}$. If borrowing constraints bind for young workers in the $\hat{\theta}$ economy, $\hat{\delta}_{\hat{F}^{\prime}}<1$, then $T^{\prime} \in$ $\left\{\hat{F}^{\prime}, \hat{F}^{\prime}-1\right\}$.

\section{Proof in Appendix.}

Both the frontier vintage and the terminal vintage are younger in the $\theta$ economy. When borrowing constraints are binding for young workers in the $\hat{\theta}$ economy, the technological overlap of skilled agents across the two economies is at most one. Then, in equilibrium, the share of agents in the world who migrate to produce with foreign agents is not large. Since younger vintages are associated with higher lifetime earnings, a higher level of per capita income is observed in the $\theta$ economy. Intuitively, the sorting across vintages is the direct consequence of the single crossing property of indifferences curves between agents who face different borrowing constraints.

"Technology cycles", the pattern in which new technologies are first learned exclusively in rich countries and are gradually transferred to poor countries, is an equilibrium feature of the analysis. These cycles are the outcome of low borrowing constraint economies delegating the steep earnings profiles activities in the world to high borrowing constraint economies. Under labour mobility, the former economies can learn new technologies without having to experience steep earnings profiles if they wait until strong enforcement economies are in a position to exploit the complementarity between skilled and unskilled labour in production. The latter allows the $\hat{\theta}$ economy to adopt new technologies through a earnings path which is shallow relative to outcomes without labour mobility. As technologies age, they become more standardised as workers can command higher wages while learning a given set of skills. Agents from poor countries with equal access to the technology frontier as rich countries, wait for technologies to become standardised to a given level before adopting them from rich countries.

\section{Proposition 3 With international labour mobility,}

(i) Worker wages within vintages are bounded by the worker wages

of the two economies under no mobility $\hat{w}_{\tau} \leq w_{\tau}^{\prime} \leq w_{\tau}$ for all $\tau$ such that $n_{\tau}^{\prime}>0$.

(ii) The terminal vintage in the world, $\hat{T}^{\prime}$, is bounded by the terminal 


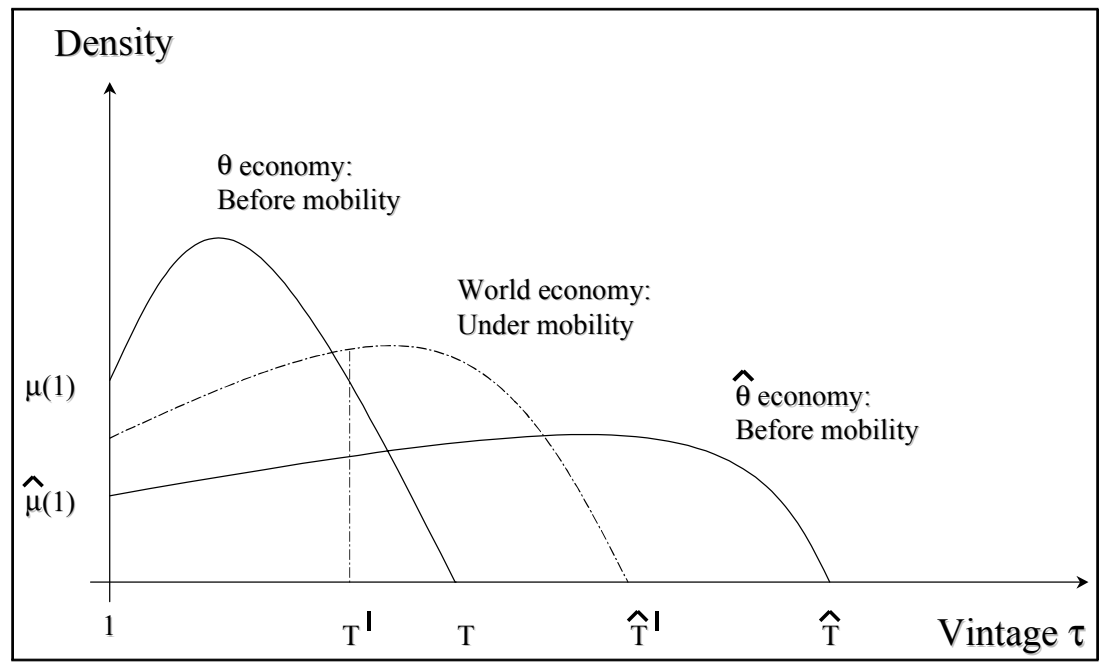

Figure 3: Density of skilled agents under international labour mobility

vintage of the two economies under no mobility $T \leq \hat{T}^{\prime} \leq \hat{T}$. The terminal vintage of the $\theta$ economy can be older or younger $T \lessgtr T^{\prime}$.

(iii) $\hat{\mu}$ stochastically dominates $\mu^{W}, \mu^{W}$ stochastically dominates $\mu$,

$$
\sum_{\tau=1}^{S} \hat{\mu}_{\tau} \leq \frac{\sum_{\tau=1}^{S}\left[\mu_{\tau}^{\prime}+\hat{\mu}_{\tau}^{\prime}\right]}{2} \leq \sum_{\tau=1}^{S} \mu_{\tau} \text { for } \forall S \leq \hat{T}
$$

Proof in Appendix.

Intuitively, the pattern of technology diffusion and the range of coexisting technologies used in the world under labour mobility, is bounded by the pattern of technology use in the two economies without labour mobility. [Figure 3] plots the distribution of skilled agents across vintages in each economy under no mobility, together with the world distribution of skilled agents with mobility. Compared to the $\theta$ economy, the world economy with mobility exhibits slower technology diffusion and older terminal vintage. Compared to the $\hat{\theta}$ economy, the world economy with mobility exhibits faster technology diffusion and younger terminal vintage. Thus, the introduction labour mobility can never increase the age of the terminal vintage in the world.

The impact of labour mobility on the relative per capita output between the two economies depends on the difference in their borrowing constraints. Consider epsilon differences in borrowing constraints between the two economies: $\hat{\theta}=\theta-\varepsilon$. This corre- 
sponds to the case where all three curves in [Figure 3] merge into one curve. Labour mobility is associated with negligible changes in worker wages but large changes in the distribution of agents across technologies. $\theta$ economy agents are sorted into high earnings new technologies and $\hat{\theta}$ economy agents are sorted into low earnings old technologies. The ratio of per capita incomes across the two economies, $\frac{y(\theta)}{y(\hat{\theta})}$ must increase. Given much larger differences in borrowing constraints $\hat{\theta}<<\theta$, the sorting of agents across technologies is accompanied by large efficiency gains in the level of world output. This introduces the possibility of higher TFP observed in the $\hat{\theta}$ economy. Overall, this may also imply that the ratio of per capita income differences $\frac{y(\theta)}{y(\hat{\theta})}$, is lower with labour mobility: TFP convergence.

[Figure 4] shows the combination of young and old period earnings experienced by agents from both economies under labour mobility. These combinations are mapped along the lower envelope of the indifferences curves of agents from the two economies. Agents from both economies must be on higher indifference curves as a result of labour mobility. In the $\theta$ economy $w_{1}^{\prime}<w_{1}$ ensures lifetime utility is higher for young workers entering the frontier vintage. In the $\hat{\theta}$ economy, $w_{\hat{T}^{\prime}-1}^{\prime}<\hat{w}_{\hat{T}-1}$ ensures lifetime utility is higher for young workers entering the penultimate vintage. Since participation constraints require lifetime utility to be the same within economies, steady state outcomes with labour mobility increases the lifetime utility of everyone in the world.

Recall that if workers are indifferent between working with entrepreneurs and working with intermediate goods produced by entrepreneurs, then outcomes under international labour mobility are interpreted as outcomes under trade in intermediate goods. Since a variety of such intermediate goods associated with different technologies, and rankable by their TFP levels, are traded, there is trade in vertically differentiated intermediate goods. Such trade is associated with two forces. First, poor countries specialise in the use older technologies for which they have a comparative advantage. Second, under trade, workers in poor countries have access to a faster rate of technology standardisation, which in turn induces faster technology adoption. This accelerated technology diffusion, is the result of workers in poor countries being able to command higher wages while learning a given set of technology specific skills. Even though poor countries specialise 


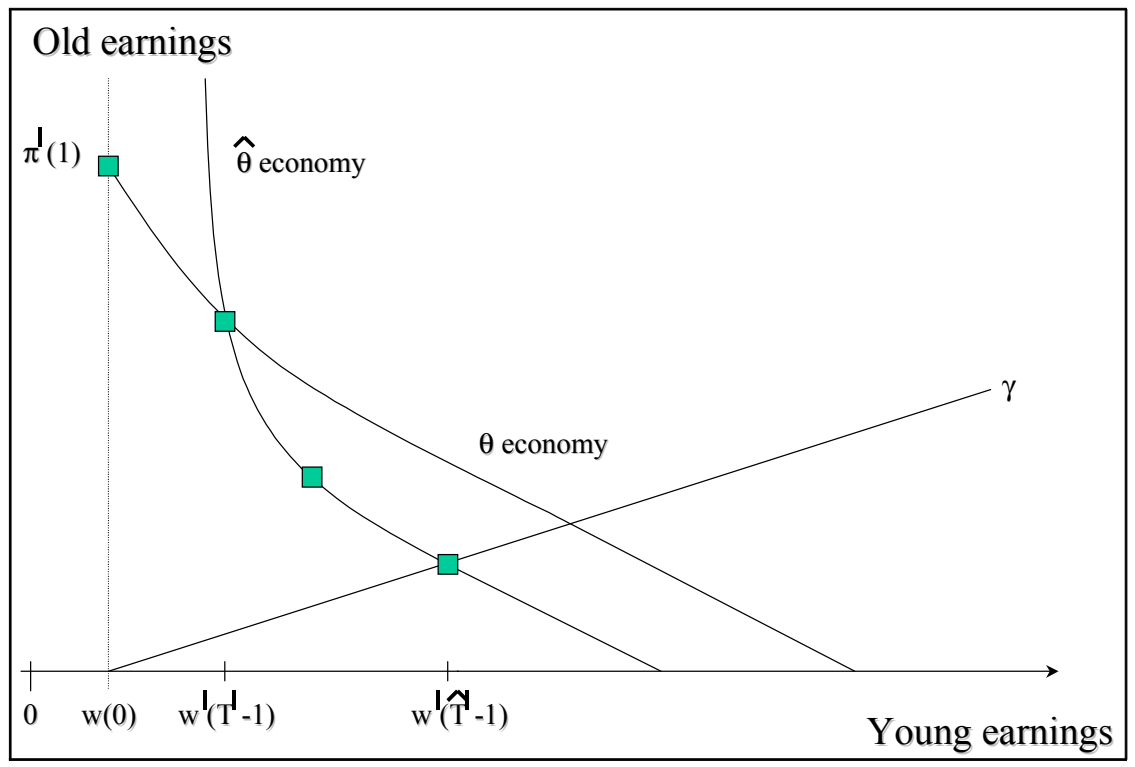

Figure 4: Earnings combinations with international labour mobility

in the old technologies of the world, the efficiency gains resulting from delegating high TFP activities to rich countries can result in the overall TFP of poor countries rising as a result of intermediate goods trade. Finally, note that the volume of trade in intermediate goods is not large. In particular, from Lemma 1, when borrowing constraints bind for young workers in the $\hat{\theta}$ economy, the number of vintages of intermediate goods traded is at most two.

\subsection{Final goods trade}

Here I do not allow for international labour mobility (or intermediate goods trade), and see what happens when economies differentiated by borrowing constraints trade in vertically differentiated final goods. I begin by showing how the model accommodates vertically differentiated final goods and perform comparative statics with the level of borrowing constraint. Then the implications of trade in vertically differentiated final goods are analysed.

Technology specific goods are now differentiated by quality which is defined in terms of Lancasterian characteristics. The quality of goods is indexed by $z \geq 0$, and there 
is a continuum of characteristics indexed by $\xi \geq 0$. Each unit of good $z$ provides one unit of the characteristics $\xi \in[0, z]$. Following Stokey (1991), household preferences are additively separable and symmetric across characteristics. In period $t$, the utility derived from an allocation of goods, of measure $q_{t}(z)$ over qualities, is given by,

$$
c_{t}=\int_{\xi=0}^{\infty} v\left(\sum_{z=\xi}^{\infty} q_{t}(z)\right) d \xi
$$

where $v$ is strictly increasing, strictly concave and $v(0)=0 .{ }^{11} \mathrm{I}$ assume preferences are homothetic across goods.

I now interpret new technologies as introducing new goods, where the quality index of the frontier good increases by a factor $\gamma$ in each period. Let $x_{\tau}$ denote the steady state measure of goods produced using vintage $\tau$ technologies, the quality index of which increases by a factor $\gamma$ each period. The quality $z=1$ good is the numeraire. Homothetic preferences imply that relative prices are functions of the aggregate supply of goods of different quality, and independent of the distribution of income in the economy. In steady states, the date $t$ relative price of the vintage $\tau$ good is given by $\gamma^{t} p_{\tau}$ where,

$$
\begin{aligned}
p_{\tau} & =p_{\tau}\left(\frac{x_{1}}{x_{0}}, \frac{x_{2}}{x_{0}}, \ldots, \frac{x_{T-1}}{x_{0}}\right) \\
& =\frac{v^{\prime}\left(\sum_{s=0}^{T-1} x_{s}\right)+(\gamma-1) v^{\prime}\left(\sum_{s=0}^{T-2} x_{s}\right)+\ldots+\gamma^{T-2-\tau}(\gamma-1) v^{\prime}\left(\sum_{s=0}^{\tau} x_{s}\right)}{\gamma^{T-1} v^{\prime}\left(\sum_{s=0}^{T-1} x_{s}\right)} \text { if } 0 \leq \tau \leq T-1 \\
& =\frac{1}{\gamma^{\tau}} \text { if } \tau \geq T-1
\end{aligned}
$$

From the concavity of $v(\cdot)$, the ratio $\frac{p_{\tau-1}}{p_{\tau}} \geq \gamma$ is falling in $\tau$ and strictly greater than $\gamma$ for all $\tau \leq T-1$.

A considerable aid to the exposition is to redefine worker wages in terms of the price of final goods they produce, define $w_{\tau} \equiv p_{\tau} \nu_{\tau}$ for all $\tau \geq 1$. This implies that entrepreneur earnings can be rewritten as, $\pi_{\tau}\left(p_{\tau}, w_{\tau}\right)=p_{\tau} \tilde{\pi}\left(\nu_{\tau}\right)$ : defining worker wages in this way allows us to separate out the output price component and worker wage component of entrepreneur earnings differences across vintages. Note that the input demand within vintages can now be expressed as, $n_{\tau}\left(w_{\tau}\right)=\tilde{n}\left(\nu_{\tau}\right)$. Since $\omega_{0}$ defines the output of vintage

\footnotetext{
${ }^{11}$ If $v$ is linear, the analysis collapses to that of the homogenous output economy.
} 
$\tau=0$ goods produced in the frontier technology by workers producing alone, they earn $w_{0}=p_{0} \omega_{0}$.

A stationary competitive equilibrium is defined as in the case of the economy with homogenous output, subject to some modifications. Now an equilibrium consists of a stationary collection of earning profiles $p_{\tau} \nu_{\tau}, p_{\tau} \tilde{\pi}\left(\nu_{\tau}\right)$, input demands $\tilde{n}\left(\nu_{\tau}\right)$, distribution function $\mu$ and prices $p_{\tau}$ such that $(i)$ young and old agents maximise their utility, (ii) the full employment constraint is satisfied, (iii) the market for goods of each quality clears: $x_{\tau}=\mu_{\tau} f\left(\tilde{n}\left(\nu_{\tau}\right)\right)$ for all $0 \leq \tau \leq T-1$.

Equilibrium participation constraints are modified as follows,

$$
\begin{aligned}
\left(p_{0} \omega_{0}+\frac{\gamma}{R} p_{1} \tilde{\pi}\left(\nu_{1}\right)\right) \delta_{1} & =\left(p_{1} \nu_{1}+\frac{\gamma}{R} p_{2} \tilde{\pi}\left(\nu_{2}\right)\right) \delta_{2}=\ldots \\
& =\left(p_{T-2} \nu_{T-2}+\frac{\gamma}{R} \frac{1}{\gamma^{T-1}} \tilde{\pi}\left(\nu_{T-1}\right)\right) \delta_{T-1} \\
& =\left(\frac{1}{\gamma^{T-1}} \nu_{T-1}+\frac{\gamma}{R} \frac{1}{\gamma^{T-1}} \nu_{T-1}\right) \delta_{T}
\end{aligned}
$$

Given the relationship between prices $p_{\tau}$, note that as before the steepness of the lifetime earnings profile must be falling in vintage. Noting that $p_{T-1}=\frac{1}{\gamma^{T-1}}$ and $p_{T}=\frac{1}{\gamma^{T}}$, the conditions on the terminal vintage are modified as follows,

$$
\tilde{\pi}\left(\nu_{T-1}\right)>\nu_{T-1} \geq \frac{1}{\gamma} \tilde{\pi}\left(\nu_{T-1}\right)
$$

The vintage for which $\nu_{\tau-1}$ falls within this range determines the age of the terminal vintage $T$.

\subsubsection{Differences in borrowing constraints}

I use a simple example to flesh out the main mechanisms and then present the general results. Consider an equilibrium economy where $T=2$ and borrowing constraints are binding in the economy (i.e. $\delta_{1}<1$ ). Participation constraints determine the vintage 1 worker wage, given $\theta, R, p_{0}$ and $p_{1}$,

$$
\left(p_{0} \omega_{0}+\frac{\gamma}{R} p_{1} \tilde{\pi}\left(\nu_{1}\right)\right) \delta_{1}\left(R \frac{p_{0}}{p_{1}} \frac{\omega_{0}}{\gamma \tilde{\pi}\left(\nu_{1}\right)} ; \theta\right)=\left(p_{1} \nu_{1}+\frac{\gamma}{R} p_{1} \nu_{1}\right) \delta_{2}\left(R \frac{1}{\gamma} ; \theta\right)
$$


The share of skilled agents in vintage 2 is equal to half the input demand of skilled agents in vintage 1 ,

$$
\mu_{2}=1-\mu_{1}=\mu_{1} \frac{\tilde{n}\left(\nu_{1}\right)}{2}
$$

Two quality differentiated goods are produced, where their market clearing conditions are given by, $x_{0}=\mu_{1} \omega_{0}$ and $x_{1}=\mu_{1} f\left(\tilde{n}\left(\nu_{1}\right)\right)$. The relative prices of quality differentiated goods (normalised by $\gamma^{t}$ ) are given by,

$$
\begin{aligned}
& p_{0}=\frac{v^{\prime}\left(x_{0}+x_{1}\right)+(\gamma-1) v^{\prime}\left(x_{0}\right)}{\gamma v^{\prime}\left(x_{0}+x_{1}\right)}=1+\frac{(\gamma-1)\left[v^{\prime}\left(x_{0}\right)-v^{\prime}\left(x_{0}+x_{1}\right)\right]}{\gamma v^{\prime}\left(x_{0}+x_{1}\right)} \\
& p_{1}=\frac{v^{\prime}\left(x_{0}+x_{1}\right)}{\gamma v^{\prime}\left(x_{0}+x_{1}\right)}=\frac{1}{\gamma} \quad \text { and } p_{\tau}=\frac{1}{\gamma^{\tau}} \text { for all } 1 \leq \tau
\end{aligned}
$$

Now, relative to this benchmark economy, young workers in another economy face lower borrowing possibilities as a share of their future income, $\hat{\theta}<\theta$. Variables relating to this second economy are denoted with hats. The marginal disutility of lower $\theta$ is greater for the steeper, new technology earnings path. Indirect utility across occupations can only be equalised again if the relative discounted value of lifetime earnings for the new technology occupation increases. Given $p_{0}$ and $p_{1}$, the latter can only be achieved through a lower $\hat{\nu}_{1}<\nu_{1}$.

From $(22)$, the implied increase in input demand $\tilde{n}\left(\nu_{1}\right)$, translates into a shift in the distribution of skilled agents away from the new technology occupation, $\hat{\mu}_{1}<\mu_{1}$. Thus, in this second economy the ratio of vintage 0 output over vintage 1 output falls, $\frac{\hat{x}_{0}}{\hat{x}_{1}}=\frac{\omega_{0}}{f\left(\tilde{n}\left(\hat{\nu}_{1}\right)\right)}<\frac{x_{0}}{x_{1}}=\frac{\omega_{0}}{f\left(\tilde{n}\left(\nu_{1}\right)\right)}$. Since vintage 1 worker wages are lower, the terminal vintage conditions for $T=2$ in (20) may no longer be satisfied (i.e. $\hat{p}_{2} \tilde{\pi}\left(\hat{\nu}_{1}\right)>\hat{p}_{1} \hat{\nu}_{1}$ ), in which case, the number of coexisting vintages in the economy will expand, $\hat{T}>T$. In this example economy, I assume the case where the age of the terminal vintage does not change $\hat{T}=T=2$. This will simplify things when I analyse the impact of trade on these example economies. Then, equilibrium relative prices of quality differentiated goods in the $\hat{\theta}$ economy are given by,

$$
\begin{aligned}
& \hat{p}_{0}=1+\frac{(\gamma-1)\left[v^{\prime}\left(\hat{x}_{0}\right)-v^{\prime}\left(\hat{x}_{0}+\hat{x}_{1}\right)\right]}{\gamma v^{\prime}\left(\hat{x}_{0}+\hat{x}_{1}\right)}>p_{0} \\
& \hat{p}_{1}=p_{1}=\frac{1}{\gamma} \quad \text { and } p_{\tau}=\hat{p}_{\tau} \text { for all } 1 \leq \tau
\end{aligned}
$$


While lower borrowing constraints discourage entry into younger vintages, the resulting reallocation of agents across vintages leads to relative price changes which encourage entry into younger vintages. Thus, relative price changes under autarchy, dampen the effect of borrowing constraints on the distribution of agents across vintages. Lemma 2 summarises the general results which are similar to those of Proposition 2.

Lemma 2 Compare two economies with different borrowing constraints $\hat{\theta}<\theta$, where $\delta_{1}<1$, then,

(i) $\hat{\nu}_{\tau}<\nu_{\tau}, \tilde{n}\left(\hat{\nu}_{\tau}\right)<\tilde{n}\left(\nu_{\tau}\right)$ and $\hat{\delta}_{\tau} \leq \delta_{\tau}$ for all $\tau$ where $\mu_{\tau}>0$

(ii) the terminal vintage is older in the $\hat{\theta}$ economy $\hat{T} \geq T$

(iii) $\hat{\mu}$ stochastically dominates $\mu$,

$$
\sum_{\tau=1}^{S} \hat{\mu}_{\tau}<\sum_{\tau=1}^{S} \mu_{\tau} \text { for } \forall S<\hat{T}
$$

(iv) Comparing the $\hat{\theta}$ economy and $\theta$ economy under autarchy, the ratio of relative prices $\frac{\hat{p}_{\tau}}{p_{\tau}}$ is strictly falling in vintage until $\frac{\hat{p}_{\hat{T}-1}}{p_{\hat{T}-1}}=1$.

Proof in Appendix.

\subsubsection{Impact of final goods trade}

Consider two coexisting economies of equal size, economy $\theta$ and economy $\hat{\theta}$, where $\theta>\hat{\theta}$. Denote by dashes all variables relating to outcomes with free trade in vertically differentiated final goods. Under free trade, market clearing requires $x_{\tau}^{\prime}+\hat{x}_{\tau}^{\prime}=$ $\mu_{\tau}^{\prime} f\left(\tilde{n}\left(\nu_{\tau}^{\prime}\right)\right)+\hat{\mu}_{\tau}^{\prime} f\left(\tilde{n}\left(\hat{\nu}_{\tau}^{\prime}\right)\right)$ for all $0 \leq \tau$. The modified full employment constraint is $\sum_{\tau=1}^{\infty}\left[\mu_{\tau}^{\prime}+\hat{\mu}_{\tau}^{\prime}\right]=2$.

Recall the two example economies from above. Begin by holding the quantity of output across differentiated goods constant in both economies. The ratio of vintage 0 output over vintage 1 output in the world is bounded by the ratio of output of the two economies under autarchy, $\frac{\hat{x}_{0}}{\hat{x}_{1}}<\frac{\hat{x}_{0}+x_{0}}{\hat{x}_{1}+x_{1}}<\frac{x_{0}}{x_{1}}$. The ratio of relative prices under trade is also bounded analogously, $\frac{\hat{p}_{0}}{\hat{p}_{1}}>\frac{p_{0}^{\prime}}{p_{1}^{\prime}}>\frac{p_{0}}{p_{1}}$. Since $\hat{p}_{1}=p_{1}^{\prime}=p_{1}$, this implies that $\hat{p}_{0}>p_{0}^{\prime}>p_{0}$. Consider the implications of these relative price changes on the participation constraints. In the $\theta$ economy, trade encourages further entry into the new technology. In the $\hat{\theta}$ economy, trade discourages entry into the new technology. 
To satisfy participation constraints in the $\theta$ economy, $\nu_{1}$ must rise so $\nu_{1}^{\prime}>\nu_{1}$. The implied decrease in input demand $n\left(\nu_{1}\right)$, translates into a shift in the distribution of agents away from the old technology occupation, $\mu_{1}^{\prime}>\mu_{1}$. In the $\hat{\theta}$ economy, the opposite occurs. To satisfy participation constraints in the $\hat{\theta}$ economy, $\hat{\nu}_{1}$ must fall so $\hat{\nu}_{1}^{\prime}<\hat{\nu}_{1}$. The implied increase in input demand $n\left(\hat{\nu}_{1}\right)$, translates into a shift in the distribution of agents away from the new technology occupation, $\hat{\mu}_{1}^{\prime}<\hat{\mu}_{1}$. Intuitively, the steady state relative price differences which exist before trade dampen the effect of borrowing constraints on the distribution of agents across technologies. Under trade in final goods, such relative price differences are equalised. Thus, final goods trade amplifies the effect of borrowing constraints on the distribution of agents across vintages.

Proposition 4 summarises the general results of the effects of vertically differentiated final goods trade on the pattern of specialisation across vintages.

Proposition 4 Compare two economies with different binding borrowing constraints $\hat{\theta}<\theta$, before and after trade:

(i) in the $\theta$ economy worker wages in each vintage are higher $p_{\tau}^{\prime} \nu_{\tau}^{\prime}>p_{\tau} \nu_{\tau}$, and the terminal vintage is younger $T^{\prime} \leq T$ under trade

(ii) $\mu$ stochastically dominates $\mu^{\prime}$,

$$
\sum_{\tau=1}^{S} \mu_{\tau}<\sum_{\tau=1}^{S} \mu_{\tau}^{\prime} \text { for } \forall S<T
$$

(iii) in the $\hat{\theta}$ economy worker wages in each vintage are lower $\hat{p}_{\tau}^{\prime} \hat{\nu}_{\tau}^{\prime}<\hat{p}_{\tau} \hat{\nu}_{\tau}$, and the terminal vintage is older $\hat{T}^{\prime} \geq \hat{T}$ under trade (iv) $\hat{\mu}^{\prime}$ stochastically dominates $\hat{\mu}$,

$$
\sum_{\tau=1}^{S} \hat{\mu}_{\tau}^{\prime}<\sum_{\tau=1}^{S} \hat{\mu}_{\tau} \text { for } \forall S<\hat{T}^{\prime}
$$

Proof in Appendix.

Barriers to trade encourage "excessive" entry into high quality production in the $\hat{\theta}$ economy. Under free trade, the distribution of agents across vintages is associated with slower technology diffusion and an older terminal vintage. In the $\theta$ economy, the opposite is true. Barriers to trade encourage excessive entry into relatively low quality 


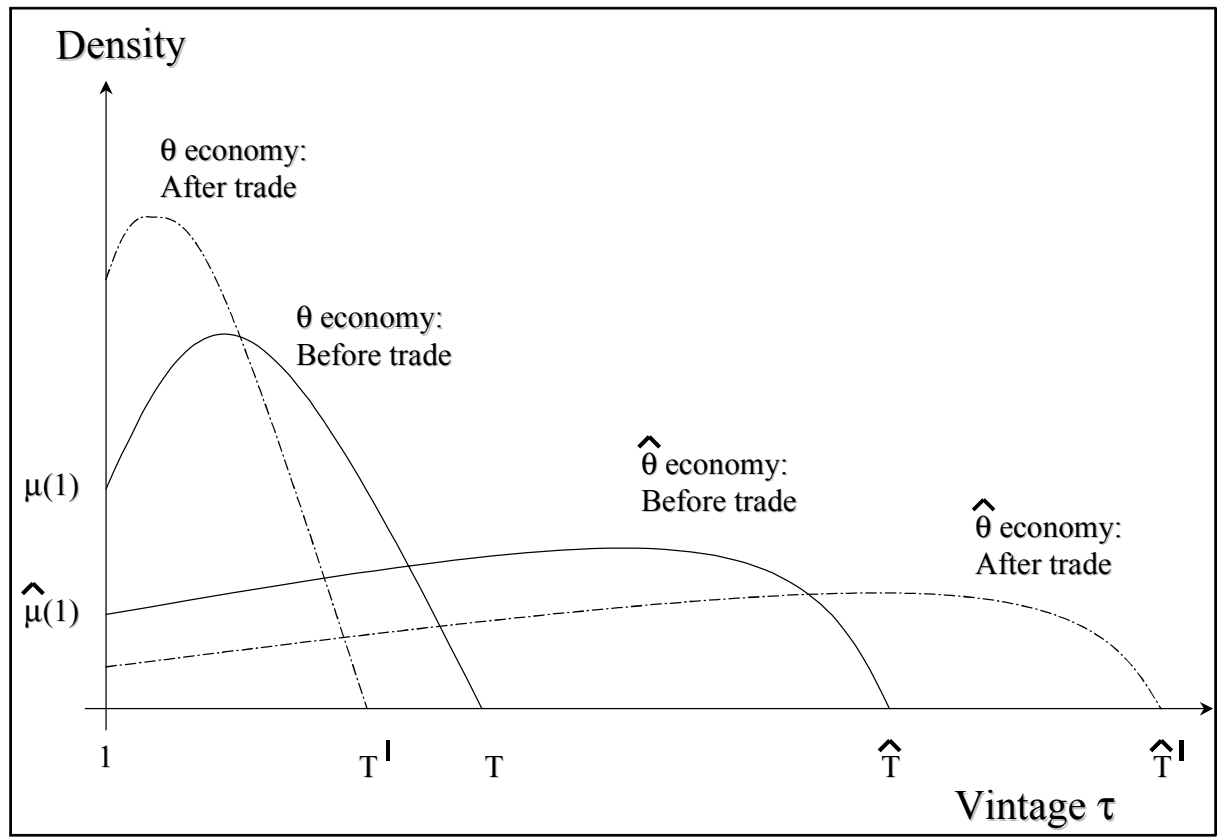

Figure 5: Density of skilled agents under final goods trade

production. Under free trade, the distribution of agents across vintages is associated with faster technology diffusion and a younger terminal vintage. [Figure 5] summaries changes in the distribution of skilled agents across vintages caused by free trade in vertically differentiated final goods.

The introduction of trade definitely improves steady state welfare in the $\theta$ economy. Since $p_{T^{\prime}-1}^{\prime} \nu_{T^{\prime}-1}^{\prime}>p_{T-1} \nu_{T-1}$, lifetime welfare has increased for young workers entering the penultimate vintage. From the participation constraints this ensures that welfare has increased throughout the $\theta$ economy. In the $\hat{\theta}$ economy, the opposite happens to the worker wage of the penultimate technology, but trade may still be associated with higher steady state welfare from the relative price fall of high quality products.

\section{Conclusion}

This paper developed a theory of TFP differences arising from exogenous differences in institutions which enforce external investor rights. In the context of technology diffusion, such differences generated many of the stylised facts about technologies in poorer 
countries. Although, trade and factor mobility may be a force for faster technology adoption and welfare gains, I have shown how some forms of international interaction may not lead to TFP convergence while divergence is predicted under some scenarios.

Future work should try to verify the links between episodes of institutional reform of external investor rights and accelerated output growth. Institutional reforms constitute a fall in the "barriers to technology adoption" in my framework. Parente and Prescott (1994) define countries which experienced reductions in such barriers as having accelerated growth relative to the U.S. over a sustained period. A further round of such event studies should focus on the impact of trade in generating the predicted pattern of specialisation across technologies in the data. In particular, it would be interesting to compare industries where trade has predominantly occurred in intermediate goods versus those in which trade has been dominated by final goods.

The implications of the theory may also be applied to related issues. One potential application is in understanding residual inequality dynamics between rich and poor nations and their relation to trade. Large increases in residual inequality have been well documented in rich countries since the early 1970s. ${ }^{12}$ An independent role for trade in explaining these dynamics has been hindered by three facts: during the period considered (i) job reallocations have occurred within industries as opposed to between industries, (ii) the volume of trade has not increased dramatically and (iii) trade is empirically associated with increased residual inequality in poor countries as well [Zhu and Trefler (2001)]. It is possible to argue that the intermediate goods trade considered in this paper, can lead to increased residual inequality in rich and poor nations, even when the volume of such trade is not large. Recall every agent devotes their youth to learning technologies and acquires skills in old age. An equilibrium feature of workers in newer technologies is their old period component of lifetime earnings is larger. Then, if skill acquisition is stochastic, lifetime inequalities are greater in newer technologies. When trade in intermediate goods causes both rich and poor countries to use newer technologies overall, this would predict greater residual inequality across the world. This would challenge the mature explanations for inequality dynamics in the literature which have

\footnotetext{
${ }^{12}$ Acemoglu (2001) provides a review of the related empirical and theoretical literature.
} 
focused on skill biased technological change or major technological change. 


\section{References}

[1] Acemoglu, Daron (2001) "Technical Change, Inequality, and The Labor Market," Journal of Economic Literature, forthcoming.

[2] Acemoglu, Daron, Simon Johnson and James A. Robinson (2001) "The Colonial Origins of Comparative Development," American Economic Review, forthcoming.

[3] Atkinson, Anthony and Joseph Stiglitz (1969) "A New View of Technological Change," Economic Journal, LXXIX, pp. 573-578.

[4] Beck, Thorsten, Ross Levine and Norman Loayza (2000) "Finance and the Sources of Growth," Journal of Financial Economics, vol. 58.

[5] Cameron, Rondo et al. (1967) "Banking in the Early Stages of Industrialization: A Study in Comparative Economic History," New York: Oxford University Press.

[6] Caselli, Francesco and Wilbur John Coleman (2000) "The World Technology Frontier," NBER Working Paper 7904.

[7] Chari, V. V. and Hopenhayn, Hugo (1991) "Vintage Human Capital, Growth, and the Diffusion of New Technology," Journal of Political Economy, vol. 99, no. 6, pp. 1142-1165.

[8] Coe, D. and E. Helpman (1995) "International R\&D Spillovers," European Economic Review, vol. 39, pp. 859-887.

[9] Coe, D., E. Helpman and A. Hoffmaister (1997) "North-South spillovers," Economic Journal, vol. 107, pp. 134-149.

[10] Goldsmith, Raymond W. (1969) "Financial Structure and Development," New Haven, CT: Yale University Press.

[11] Hall, Robert E. and Charles I. Jones (1999) "Why do Some Countries Produce so Much More Output than Others?" Quarterly Journal of Economics, CXIV, pp. 83-116.

[12] Keller, Wolfgang (2001) "International Technology Diffusion," Working Paper: University of Texas.

[13] Keller, Wolfgang (1998) "Are international R\&D Spillovers Trade Related? Analysing Spillovers Among Randomly Matched Trade Partners," European Economic Review, vol. 42, pp. 1469-1481.

[14] King, Robert G. and Ross Levine (1993) "Finance and Growth: Schumpeter Might be Right," Quarterly Journal of Economics, vol 108(3), pp. 717-737.

[15] Klenow, Peter and Rodriguez-Clare (1997) "The Neoclassical Revival in Growth Economics: Has it Gone Too Far?" NBER Macroeconomics Annual, 73-114. 
[16] Krusell, Per and Jose-Victor Rios-Rull (1996) "Vested Interests In a Positive Theory of Stagnation and Growth," Review of Economic Studies, vol. 63, pp. 301-331.

[17] Lancaster, Kevin (1966) "A New Approach to Consumer Theory," Journal of Political Economy, vol. 74, pp. 132-157.

[18] La Porta, Rafael, Florencio Lopez-de-Silanes, Andrei Shleifer and Robert W. Vishny (1997) "Legal Determinants of External Finance," Journal of Finance 52, 11311150 .

[19] La Porta, Rafael, Florencio Lopez-de-Silanes, Andrei Shleifer and Robert W. Vishny (1998) "Law and Finance," Journal of Political Economy 106, 1113-1155.

[20] Levine, Ross (1997) "Financial Development and Economic Growth: Views and Agenda," Journal of Economic Literature, vol. 35, pp. 688-726.

[21] Parente, Stephen L. and Prescott, Edward C. (1994) "Barriers to Technology Adoption and Development," Journal of Political Economy, vol. 102, no. 2, pp. 298-321.

[22] Prescott, Edward C. (1998) "Needed: A Theory of Total Factor Productivity," International Economic Review, vol. 39, pp. 525-51.

[23] Rajan, Raghuram and Luigi Zingales (2001) "The Great Reversals: The Politics of Financial Development in the 20th Century," NBER Working Paper 8178.

[24] Rodriguez, Francisco and Dani Rodrik (1999) "Trade Policy and Economic Growth: A Skeptic's Guide to Cross-National Evidence," NBER Working Paper 7081.

[25] Stokey, Nancy (1991) "Human Capital, Product Quality and Growth," Quarterly Journal of Economics, vol. pp. 587-616.

[26] Thompson, Peter (1999) "Technology Diffusion, Vintage Human Capital and the Age-Earnings Profile: A Test with the International Merchant Marine, 1872-1912," Working paper: University of Houston.

[27] Wurgler, Jeffrey (2000) "Financial Markets and the Allocation of Capital," Journal of Financial Economics, vol. 58.

[28] Zhu, Susan C. and Daniel Trefler (2001), "Ginis in General Equilibrium: Trade, Technology and Southern Inequality," NBER Working Paper 8446. 


\section{Appendix}

Proof of Proposition 1. First show that if $\mu_{T}=0$ for some $T \Rightarrow \mu_{T+1}=0$. Suppose $\mu_{T}=0, \mu_{T+1}>0 \Rightarrow w_{T}=\gamma^{-T} \omega_{0}, w_{T-1} \geq \gamma^{-T+1} \omega_{0} \Rightarrow w_{T}<w_{T-1}$. This must imply that $\pi_{T}\left(w_{T}\right)<\pi_{T+1}\left(w_{T+1}\right)$, but using the definition of $\pi_{\tau}\left(w_{\tau}\right)$, and noting that $w_{T+1} \geq \gamma^{-T-1} \omega_{0}$ this leads to a contradiction.

Second show that $T=\infty$ leads to a contradiction. Begin by supposing that $w_{\tau} \geq$ $w_{\tau+1} \geq \gamma^{-\tau-1} \omega_{0} \Rightarrow \pi_{\tau} \leq \pi_{\tau+1}, \delta_{\tau}>\delta_{\tau+1}$. Using the definition of $\pi_{\tau}\left(w_{\tau}\right)$, and noting that $w_{\tau} \geq \gamma^{-\tau} \omega_{0}$ this leads to a contradiction. Next suppose $w_{\tau}<w_{\tau+1} \Rightarrow \pi_{\tau} \geq \pi_{\tau+1}, \delta_{\tau} \leq$ $\delta_{\tau+1}$. Since $\pi_{\tau}\left(w_{\tau}\right)$ is falling in worker wages and vintage, the claim is contradicted.

Next show that $w_{\tau}<w_{\tau+1}$ for all $\tau$ with $\mu_{\tau}>0$. Let $T$ be the terminal vintage. Suppose $w_{T-2} \geq w_{T-1} \Rightarrow \pi_{T}\left(w_{T}\right) \geq \pi_{T-1}\left(w_{T-1}\right)$. Since $T$ is the terminal vintage, $\max w_{s}>\pi_{T}\left(w_{T}\right)$ and we have a contradiction. By induction worker wages are increas-

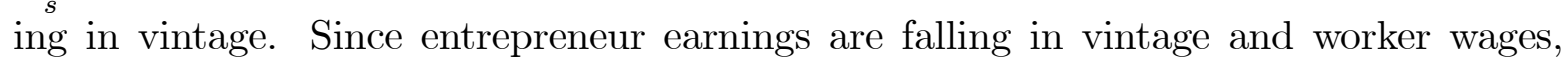
entrepreneur earnings are falling in vintage and the steepness of the lifetime earnings profile is falling in vintage. Thus, given borrowing constraints are binding $\delta_{\tau}<\delta_{\tau+1}$.

The existence proof of a unique stationary equilibrium can directly appeal to Proposition 2 and the Theorem in Chari and Hopenhayn (1991).

Proof of Proposition 2. First show that $w_{\tau}>\hat{w}_{\tau}$. Suppose $w_{1} \leq \hat{w}_{1}$, from (10) this implies that $w_{2} \leq \hat{w}_{2}$, and by induction $w_{\tau} \leq \hat{w}_{\tau}$, all $\tau \leq \hat{T}$. Note from (11) $\hat{T} \leq T$. Since $\frac{\partial \delta}{\partial \theta}>0$ when $\delta_{1}<1$, revealed preference implies,

$$
\begin{aligned}
k & =\left[\omega_{0}+\frac{\gamma}{R} \pi_{1}\left(w_{1}\right)\right] \delta\left(R \frac{\omega_{0}}{\gamma \pi_{1}\left(w_{1}\right)}, \theta\right)>\left[\omega_{0}+\frac{\gamma}{R} \pi_{1}\left(w_{1}\right)\right] \delta\left(R \frac{\omega_{0}}{\gamma \pi_{1}\left(w_{1}\right)}, \hat{\theta}\right) \\
& \geq\left[\omega_{0}+\frac{\gamma}{R} \pi_{1}\left(\hat{w}_{1}\right)\right] \delta\left(R \frac{\omega_{0}}{\gamma \pi_{1}\left(\hat{w}_{1}\right)}, \hat{\theta}\right)=\hat{k}
\end{aligned}
$$

and the terminal vintage conditions (11) imply,

$$
\begin{gathered}
{\left[w_{\hat{T}-1}+\frac{\gamma}{R} w_{\hat{T}-1}\right] \delta\left(R \frac{1}{\gamma}, \theta\right) \geq\left[w_{T-1}+\frac{\gamma}{R} w_{T-1}\right] \delta\left(R \frac{1}{\gamma}, \theta\right)=k} \\
{\left[w_{\hat{T}-1}(1+\beta \gamma)\right] \delta\left(\frac{1}{\gamma}, \theta\right)>\left[w_{\hat{T}-1}(1+\beta \gamma)\right] \delta\left(\frac{1}{\gamma}, \hat{\theta}\right)=\hat{k}}
\end{gathered}
$$

Using these inequalities,

$$
\begin{aligned}
& {\left[\omega_{0}+\frac{\gamma}{R} \pi_{1}\left(w_{1}\right)\right]\left(\delta\left(R \frac{\omega_{0}}{\gamma \pi_{1}\left(w_{1}\right)}, \theta\right)-\delta\left(R \frac{\omega_{0}}{\gamma \pi_{1}\left(w_{1}\right)}, \hat{\theta}\right)\right) } \\
\leq & k-\hat{k} \leq\left[w_{\hat{T}-1}+\frac{\gamma}{R} w_{\hat{T}-1}\right]\left(\delta\left(R \frac{1}{\gamma}, \theta\right)-\delta\left(R \frac{1}{\gamma}, \hat{\theta}\right)\right)
\end{aligned}
$$

But $\left[\omega_{0}+\frac{\gamma}{R} \pi_{1}\left(w_{1}\right)\right]>\left[w_{\hat{T}-1}+\frac{\gamma}{R} w_{\hat{T}-1}\right]$, and the fact that $\frac{\partial^{2} \delta}{\partial \frac{y_{1}}{y_{2}} \partial \theta} \leq 0$ contradicts the inequality. So $w_{1}>\hat{w}_{1}$, and by induction $w_{\tau}>\hat{w}_{\tau}$ for all $1 \leq \tau \leq T-1$ and $\delta_{\tau} \geq \hat{\delta}_{\tau}$ for all $1 \leq \tau \leq T$, and $\hat{T} \geq T$ from (11). 
Using the relationships between successive densities from Proposition 1 (ii), the full employment condition can be rearranged to yield the following expression for the density of skilled workers in vintage 1 ,

$$
\frac{1-\mu_{1}}{\mu_{1}}=n_{1}\left(w_{1}\right)+\left[n_{1}\left(w_{1}\right) n_{2}\left(w_{2}\right)\right]+\ldots+\left[n_{1}\left(w_{1}\right) \times \ldots \times \frac{n_{T-1}\left(w_{T-1}\right)}{2}\right]
$$

Since $\hat{T} \geq T$ and $n_{\tau}\left(w_{\tau}\right)<n_{\tau}\left(\hat{w}_{\tau}\right)$ for all $\tau \leq T-1, \mu_{1}>\hat{\mu}_{1}$. Let $Q$ be the youngest vintage such that $\hat{\mu}_{Q}>\mu_{Q}$. Since $\hat{T} \geq T, n_{\tau}\left(w_{\tau}\right)<n_{\tau}\left(\hat{w}_{\tau}\right)$, and $\mu_{1}>\hat{\mu}_{1}$ stochastic dominance follows for all $S<Q$. It also follows that $\hat{\mu}_{S}>\mu_{S}$ for all $\hat{T} \geq S \geq Q$, so $\sum_{S}^{\hat{T}} \hat{\mu}_{\tau}>\sum_{S}^{\hat{T}} \mu_{\tau}$. This implies that $1-\sum_{\tau=1}^{S-1} \hat{\mu}_{\tau}>1-\sum_{\tau=1}^{S-1} \mu_{\tau}$, which establishes the result.

Proof of Lemma 1. By way of contradiction suppose for some vintage $S, \delta_{S-1}^{\prime}<1$ and the following two conditions hold,

$$
\begin{aligned}
& {\left[w_{S-2}^{\prime}+\frac{\gamma}{R} \pi_{S-1}\left(w_{S-1}^{\prime}\right)\right] \delta_{S-1}^{\prime}=\left[w_{S-1}^{\prime}+\frac{\gamma}{R} \max \left\{\pi_{S}\left(w_{S}^{\prime}\right), w_{S-1}^{\prime}\right\}\right] \delta_{S}^{\prime}} \\
& {\left[w_{S-2}^{\prime}+\frac{\gamma}{R} \pi_{S-1}\left(w_{S-1}^{\prime}\right)\right] \hat{\delta}_{S-1}^{\prime} \geq\left[w_{S-1}^{\prime}+\frac{\gamma}{R} \max \left\{\pi_{S}\left(w_{S}^{\prime}\right), w_{S-1}^{\prime}\right\}\right] \hat{\delta}_{S}^{\prime}}
\end{aligned}
$$

This implies that,

$$
\begin{aligned}
& {\left[w_{S-2}^{\prime}+\frac{\gamma}{R} \pi_{S-1}\left(w_{S-1}^{\prime}\right)\right]\left(\delta_{S-1}^{\prime}-\hat{\delta}_{S-1}^{\prime}\right) } \\
\leq & {\left[w_{S-1}^{\prime}+\frac{\gamma}{R} \max \left\{\pi_{S}\left(w_{S}^{\prime}\right), w_{S-1}^{\prime}\right\}\right]\left(\delta_{S}^{\prime}-\hat{\delta}_{S}^{\prime}\right) }
\end{aligned}
$$

From Proposition $1\left[w_{S-2}^{\prime}+\frac{\gamma}{R} \pi_{S-1}\left(w_{S-1}^{\prime}\right)\right] \geq\left[w_{S-1}^{\prime}+\frac{\gamma}{R} \max \left\{\pi_{S}\left(w_{S}^{\prime}\right), w_{S-1}^{\prime}\right\}\right]$, so the inequality violates $\frac{\partial^{2} \delta}{\partial \frac{y_{1}}{y_{2}} \partial \theta} \leq 0$, when borrowing constraints bind. So $\left[w_{S-2}^{\prime}+\frac{\gamma}{R} \pi_{S-1}\left(w_{S-1}^{\prime}\right)\right] \hat{\delta}_{S-1}^{\prime}<$ $\left[w_{S-1}^{\prime}+\frac{\gamma}{R} \max \left\{\pi_{S}\left(w_{S}^{\prime}\right), w_{S-1}^{\prime}\right\}\right] \hat{\delta}_{S}^{\prime}$.

Proof of Proposition 3. Begin with $\hat{w}_{\tau} \leq w_{\tau}^{\prime}$. Suppose $\hat{w}_{1}>w_{1}^{\prime}$ so under mobility, indirect utility is higher if young workers from economy $\hat{\theta}$ enter the frontier vintage . Participation constraints imply that worker wages are lower in older vintages $\hat{w}_{\tau}>w_{\tau}^{\prime}$. Since workers from the $\hat{\theta}$ economy enter the terminal technology, (11) implies that the indirect utility must be lower for such agents. This is a contradiction. So $\hat{w}_{1} \leq w_{1}^{\prime}$, and by induction $\hat{w}_{\tau} \leq w_{\tau}^{\prime}$. From (11), higher worker wages implies $\hat{T}^{\prime} \leq \hat{T}$.

Next consider $w_{\tau}^{\prime} \leq w_{\tau}$. Suppose $w_{1}^{\prime}>w_{1}$ so under mobility, indirect utility is lower for young workers from economy $\theta$ entering the frontier vintage. Participation constraints imply that worker wages are higher in older technologies under mobility $w_{\tau}^{\prime}>w_{\tau}$. From (11), the latter implies that indirect utility would be higher if young workers in the $\theta$ economy enter the terminal technology, and this is a contradiction. So $w_{1}^{\prime} \geq w_{1}$, and by induction $w_{\tau}^{\prime} \geq w_{\tau}$. Result (ii) follows from the argument that the level of the highest worker wages serves as an index of the number of coexisting vintages in (11). The proof of stochastic dominance is similar to that for Proposition 2. 
Proof of Lemma 2. Given an equilibrium exists and is unique from the Theorem of Chari and Hopenhayn (1991), I verify such an equilibrium satisfies the conditions of the Lemma. If relative prices between quality differentiated products are held constant, we know from Proposition 2 that when $\hat{\theta}<\theta, \tilde{n}\left(\hat{\nu}_{v}\right)>\tilde{n}\left(\nu_{v}\right)$. The task is to prove that this implies $\frac{\hat{p}_{\tau-1}}{p_{\tau-1}}>\frac{\hat{p}_{\tau}}{p_{\tau}}$ for all $1 \leq \tau \leq T-1$. From the definition of $p_{\tau}$ and rearranging, we need to show,

$$
\begin{aligned}
& \frac{v^{\prime}\left(\sum_{s=0}^{\tau-1} \hat{x}_{s}\right)}{v^{\prime}\left(\sum_{s=0}^{\tau-1} x_{s}\right)} \\
> & \frac{v^{\prime}\left(\sum_{s=0}^{T-1} \hat{x}_{s}\right)+(\gamma-1) v^{\prime}\left(\sum_{s=0}^{T-2} \hat{x}_{s}\right)+\ldots+\gamma^{T-2-\tau}(\gamma-1) v^{\prime}\left(\sum_{s=0}^{\tau} \hat{x}_{s}\right)}{v^{\prime}\left(\sum_{s=0}^{T-1} x_{s}\right)+(\gamma-1) v^{\prime}\left(\sum_{s=0}^{T-2} x_{s}\right)+\ldots+\gamma^{T-2-\tau}(\gamma-1) v^{\prime}\left(\sum_{s=0}^{\tau} x_{s}\right)}
\end{aligned}
$$

This is true if,

$$
\frac{v^{\prime}\left(\sum_{s=0}^{\tau-1} \hat{x}_{s}\right)}{v^{\prime}\left(\sum_{s=0}^{\tau-1} x_{s}\right)}>\frac{v^{\prime}\left(\sum_{s=0}^{\tau} \hat{x}_{s}\right)}{v^{\prime}\left(\sum_{s=0}^{\tau} x_{s}\right)}>\ldots>\frac{v^{\prime}\left(\sum_{s=0}^{T-1} \hat{x}_{s}\right)}{v^{\prime}\left(\sum_{s=0}^{T-1} x_{s}\right)}
$$

For any vintage $0 \leq v \leq T-1$,

$$
\frac{v^{\prime}\left(\sum_{s=0}^{v} \hat{x}_{s}\right)}{v^{\prime}\left(\sum_{s=0}^{v} x_{s}\right)}=\frac{v^{\prime}\left(\hat{\mu}_{1}\left(\omega_{0}+f\left(\tilde{n}\left(\hat{\nu}_{1}\right)\right)+\tilde{n}\left(\hat{\nu}_{1}\right) f\left(\tilde{n}\left(\hat{\nu}_{2}\right)\right)+\ldots+\tilde{n}\left(\hat{\nu}_{1}\right) \times \ldots \times \tilde{n}\left(\hat{\nu}_{v-1}\right) f\left(\tilde{n}\left(\hat{\nu}_{v}\right)\right)\right)\right)}{v^{\prime}\left(\mu_{1}\left(\omega_{0}+f\left(\tilde{n}\left(\nu_{1}\right)\right)+\tilde{n}\left(\nu_{1}\right) f\left(\tilde{n}\left(\nu_{2}\right)\right)+\ldots+\tilde{n}\left(\nu_{1}\right) \times \ldots \times \tilde{n}\left(\nu_{v-1}\right) f\left(\tilde{n}\left(\nu_{v}\right)\right)\right)\right)}
$$

Given $\tilde{n}\left(\hat{\nu}_{v}\right)>\tilde{n}\left(\nu_{v}\right)$ the result follows. The proof of stochastic dominance is similar to that for Proposition 2.

Proof of Proposition 4. Given an equilibrium exists and is unique from the Theorem of Chari and Hopenhayn (1991), I verify such an equilibrium satisfies the conditions of the Proposition. We need to show, $\frac{\hat{p}_{\tau-1}}{\hat{p}_{\tau}}>\frac{p_{\tau-1}^{\prime}}{p_{\tau}^{\prime}}>\frac{p_{\tau-1}}{p_{\tau}}$. Using the proof in Lemma 2, an equilibrium with such relationships between prices exists if, $\tilde{n}\left(\hat{\nu}_{v}\right)>$ $\frac{\tilde{n}\left(\hat{\nu}_{v}^{\prime}\right)+\tilde{n}\left(\nu_{v}^{\prime}\right)}{2}>\tilde{n}\left(\nu_{v}\right)$.

Assuming this latter condition holds, the last step is to verify that the implied relationships between prices are consistent this assumed condition. Verifying this is sufficient to confirm the claims of the Proposition. I shall work through the proof for the $\theta$ economy. Recall the participation constraints across technologies,

$$
\begin{aligned}
\left(p_{0} \omega_{0}+\frac{\gamma}{R} p_{1} \tilde{\pi}\left(\nu_{1}\right)\right) \delta_{1} & =\left(p_{1} \nu_{1}+\frac{\gamma}{R} p_{2} \tilde{\pi}\left(\nu_{2}\right)\right) \delta_{2}=\ldots \\
& =\left(p_{T-2} \nu_{T-2}+\frac{\gamma}{R} \frac{1}{\gamma^{T-1}} \tilde{\pi}\left(\nu_{T-1}\right)\right) \delta_{T-1} \\
& =\left(\frac{1}{\gamma^{T-1}} \nu_{T-1}+\frac{\gamma}{R} \frac{1}{\gamma^{T-1}} \nu_{T-1}\right) \delta_{T}
\end{aligned}
$$

Given $\frac{p_{\tau-1}^{\prime}}{p_{\tau}^{\prime}}>\frac{p_{\tau-1}}{p_{\tau}}$ for all $\tau \leq T-1$, it must be the case that $\nu_{T-1}^{\prime}>\nu_{T-1}$. Suppose not such that $\nu_{T-1}^{\prime} \leq \nu_{T-1}$ and the indirect utility of agents is lower under trade. Since 
$\frac{p_{T-2}^{\prime}}{p_{T-1}^{\prime}}>\frac{p_{T-2}}{p_{T-1}}$ this implies $\nu_{T-2}^{\prime}<\nu_{T-2}$ and by induction $\nu_{\tau}^{\prime}<\nu_{\tau}$ for all $1 \leq \tau \leq T-2$. But since $\frac{p_{0}^{\prime}}{p_{1}^{\prime}}>\frac{p_{0}}{p_{1}}$, this means that indirect utility is higher under trade for agents entering the frontier technology, which is a contradiction. So $\nu_{T-1}^{\prime}>\nu_{T-1}$ and by induction $\nu_{\tau}^{\prime}>\nu_{\tau}$ for all $1 \leq \tau \leq T-1$ and $\tilde{n}\left(\nu_{v}^{\prime}\right)<\tilde{n}\left(\nu_{v}\right)$ for all $1 \leq v \leq T-1$. From (20) we also know $T^{\prime} \leq T$.

In the $\hat{\theta}$ economy a similar logic reveals $\tilde{n}\left(\hat{\nu}_{v}^{\prime}\right)>\tilde{n}\left(\hat{\nu}_{v}\right)$ for all $1 \leq v \leq \hat{T}-1$, and $\hat{T}^{\prime} \geq \hat{T}$. The proof is completed by observing that $\tilde{n}\left(\hat{\nu}_{v}^{\prime}\right)>\tilde{n}\left(\hat{\nu}_{v}\right)$ and $\tilde{n}\left(\nu_{v}^{\prime}\right)<\tilde{n}\left(\nu_{v}\right)$ is consistent with what was assumed, $\tilde{n}\left(\hat{\nu}_{v}\right)>\frac{\tilde{n}\left(\hat{\nu}_{v}^{\prime}\right)+\tilde{n}\left(\nu_{v}^{\prime}\right)}{2}>\tilde{n}\left(\nu_{v}\right)$. The proofs of stochastic dominance are similar to that for Proposition 2. 